Canadian University Music Review

Revue de musique des universités canadiennes

\title{
Acoustical Factors in Subjective Tests
}

\section{Floyd E. Toole}

Numéro 3, 1982

URI : https://id.erudit.org/iderudit/1013827ar

DOI : https://doi.org/10.7202/1013827ar

Aller au sommaire du numéro

\section{Éditeur(s)}

Canadian University Music Society / Société de musique des universités

canadiennes

\section{ISSN}

0710-0353 (imprimé)

2291-2436 (numérique)

Découvrir la revue

\section{Citer cet article}

Toole, F. E. (1982). Acoustical Factors in Subjective Tests. Canadian University Music Review / Revue de musique des universités canadiennes, (3), 49-66.

https://doi.org/10.7202/1013827ar

All Rights Reserved (C Canadian University Music Society / Société de musique des universités canadiennes, 1982
Ce document est protégé par la loi sur le droit d'auteur. L’utilisation des services d'Érudit (y compris la reproduction) est assujettie à sa politique d'utilisation que vous pouvez consulter en ligne.

https://apropos.erudit.org/fr/usagers/politique-dutilisation/ 


\title{
ACOUSTICAL FACTORS IN SUBJECTIVE TESTS
}

\author{
Floyd E. Toole
}

Music is to be listened to, and an important aspect of almost any musical performance is a sharing of the experience. It is well known that the acoustical environment is a major factor in the satisfaction of both performers and audience. Consequently, over the years, a great deal of effort and money have been dedicated to the design of concert halls and other performing spaces. The results have been somewhat mixed but it is safe to conclude that progress has been made at least to the point that if complete success is not assured at least failure can be avoided.

Part of the difficulty in the design of acoustical spaces for live musical performances is that the environment becomes a part of, or an extension to, the performance itself. On that basis, considerable variation can be permitted and justified solely as valid interpretations. In fact, so long as one remains in the domain of musical production, variations of all manner are permissible to the extent that they are chosen or allowed as a part of the artistic creation. As soon as we cross the boundary into sound reproduction the rules change. Here there is, by definition, the requirement that certain priorities be met - that an event be duplicated.

In the popular context this is the premise of high fidelity sound reproduction, wherein there is the notion that a musical event taking place in a recording studio or concert hall can be replicated in the home. If this can be achieved, the needs of music listeners should be well served indeed. Sadly this is an objective that, strictly speaking, is impossible or impractical to meet. The problems are principally technical and acoustical, as will be discussed later.

Fortunately, the music prevails with less than perfect reproduction and much of the desired effect is achieved. Evidence of this is in the hours of musical pleasure that we can derive from 
portable and car radios or primitive stereo systems. This notwithstanding, there is little doubt that the pleasure of the musical experience is enhanced if the listener can hear the nuances of timbre and tone that derive from the combination of talented musicians and fine instruments. On a more basic level it is also exhilarating to experience the throb of organ pedal notes and the dynamics of a large orchestra. These are all ingredients in the musical experience that almost anyone, even those most cynical of the excesses of consumer audio, can appreciate.

At a professional level, there are those engaged in scientific research aimed at understanding the processes of human auditory perception. These people conduct controlled experiments in which subjects are exposed to carefully tailored sounds and their responses recorded and analyzed. The test signals may be real music or contrived signals intended to convey some essential quality of music, such as pitch, timbre, or loudness. It is of fundamental importance, in these experiments, that the sound appearing at the listener's ears be a faithful acoustical replica of the intended test signal. If it is not or if there are factors that cause variations from time to time or from individual to individual, then the experiment has taken on a set of uncontrolled variables that are likely to be reflected as biases or random errors in the results.

Whether the requirement is for accurate sound reproduction in the home or for the accurate presentation of test stimulus at a subject's ears, the principal problems are of a physical nature. When the source of sound is loudspeakers or headphones the considerations must include the transducers as well as the acoustical coupling to the listener's ears. With loudspeakers or real musical instruments the acoustical coupling includes the listening room and the arrangement of listeners and sound sources in the room.

In the following discussion we will use, as an example, the loudspeaker reproduction of sound. The sequence of analysis will begin with a description of the sound source, a look at the interaction of the sound source with the listening room and, finally, the combination of source, room, and listener will be examined.

\section{Characterizing the Sound Source}

A loudspeaker or a musical instrument radiates a sound field that varies as a function of direction. In both, there are preferred orientations with respect to the important listeners, 
and listeners situated away from these axes hear different and perhaps less good sound.

In the case of a loudspeaker, the objective is to communicate to a listener an acoustical facsimile of a prescribed electrical signal. This is normally accomplished by designing the transducer to produce, along its principal axis, the most accurate acoustical rendering of the electrical input. This is called the "on-axis" response. At angles away from the principal axis, called "off-axis," the output will deteriorate in a manner and amount dependent upon the particular design of the speaker.

In normal listening environments the sound arriving at a listener's ears is a composite of the "direct" sound, that which travels directly from the sound source to the listener's ears, the "reflected" sounds, the off-axis radiated sound that has undergone one or two reflections from the walls, floor, or ceiling before reaching the ears, and the "reverberant" sounds that have been reflected many times and that, due to their gradual absorption by the room boundaries and furnishings, fade into inaudibility. All of these components contribute differently to different aspects of auditory perception and must therefore be considered in the technical assessments of the loudspeakers and rooms. Furthermore, unless the intended sound includes these room-dependent components they could be significantly detrimental to the accuracy of the sound reproduction.

In characterizing the physical performance of a loudspeaker, measurements are made of several parameters, the most fundamental of which is frequency response - a measure of the uniformity of sound output as a function of frequency. This, typically, is measured at a distance of two meters from the speaker, on axis and at various angles off axis, in an anechoic room or using instrumentation that can simulate anechoic data.

Figures 1 and 2 show some of the data that is used to assess the performance of a loudspeaker. Obviously, a complete description of this kind should include measurements made at a large number of points on a sphere surrounding the loudspeaker. The measurements shown are the minimum number that we have found to be useful in describing the performance of conventional loudspeakers. In the examples chosen, the loudspeakers are simple sources with symmetrical sound output to the left and right (horizontal dispersion), and only one vertical measurement is shown (the radiation upwards).

Figure 1 illustrates the results with a high-quality domestic 
loudspeaker, showing that the designer has been reasonably successful at reaching his objective of producing a transducer that radiates a sound, over a very wide bandwidth and over a very wide angle toward the listening area, that is an accurate spectral representation of the electrical input signal. Such a loudspeaker could be said to possess a relatively "flat" frequency response. This data indicates that in a typical listening room the direct sound, the early reflections, and much of the reverberant sound field will have the same basic character.

Figure 2 illustrates the performance of a well-known and widely used recording studio monitor loudspeaker. Obviously this device is much less accurate in its conversion of an electrical input into a sound field. At none of the measurement points is the frequency response as smooth or "flat" as those shown in Figure 1 and, overall, the change in performance as a function of angle off axis indicates that the sounds reaching listeners in a typical room will be of varying qualities, none of which are accurate representations of the intended sound. One may wonder at the motives that led to the widespread acceptance of this device by people professionally involved in audio. The common technical rationalization is to allude to the fact that in professional applications, as compared to domestic uses, it is more important that the loudspeaker be efficient, that is, require less amplifier power for a given output, be durable, that is, withstand prolonged use and abuse without failing, and be capable of reproducing very high sound levels, that is, sound levels much higher than consumers demand for the enjoyment of music. In the design of such loudspeakers it has been common to sacrifice the accuracy of sound reproduction to gain performance in these specific respects. At the point in the cycle of sound recording and reproduction where one needs and would expect to find highly precise sound reproduction or, at least, sound reproduction that is representative of typical or good domestic hi-fi, one instead very often finds a standard of performance rather lower and somewhat eccentric (see Toole 1979). The evidence that recordings themselves suffer and are variable as a result of this situation is in any reasonable record collection.

To anyone involved with the music, this is a regrettable injustice, but of little scientific consequence. As a measure of the status of audio, it indicates that either measurements of this type are not widely available or, if they are, are not widely accepted. At present both problems exist. As a result, anyone - scientist, 
professional audio engineer, hi-fi enthusiast, or average consumer - is in very much the same situation of not having access to comprehensive technical data on loudspeakers and, if it exists, of not knowing how to interpret it.

In an attempt to improve this state of affairs, a few individuals and groups such as the International Electrotechnical Commission (IEC) are attempting to develop scientifically valid and technically relevant measurement procedures for loudspeakers (see IEC Publication 268-5 [1972] and Toole 1977). In a parallel effort there is work on the subjective evaluation of loudspeakers (see Toole 1982 a \& b and Gabrielsson \& Sjögren 1979). The latter work discusses a number of factors as diverse as the acoustical description of the sound source, the room, and the sound field in the room, as a basis for understanding what the listener hears, and the problems of psychometrics: the ordering of listener responses on subjective scales of sound quality.

The assessment of sound quality includes the perception of many subjective dimensions that are related to musical perception. The converse is also true, that the perception of certain attributes of music are related to specific properties of the sound appearing at a listener's ears, and thereby to sound quality. Consequently, an understanding of one field can aid the other and studies in both fields are dependent upon rather precise physical knowledge of the sound at the listener's ears.

\section{The Sound Source in a Room}

The sound arriving at a listener's ears in a normal room is dependent upon a host of factors not all of which can be predicted or controlled with precision. At low frequencies particularly, the frequency response can vary considerably. Figure 3a shows the frequency response of a good domestic loudspeaker measured in a normal listening room using the same equipment that produced the curves of Figure 1. Although it is not the same loudspeaker, it is of comparable quality, by today's standards. The large undulations in the frequency response curve at frequencies below about $300 \mathrm{~Hz}$ are due simply to the room and to the position of the loudspeaker and microphone (listener) in the room. Moving either the microphone or the loudspeaker, even a few inches in any direction, can change the pattern substantially.

The variations in low-frequency frequency response are large, as much as 20 to $30 \mathrm{~dB}$ from the lowest to the highest points. In terms of perceived loudness of tones or harmonics at specific 
frequencies it means that tonal components can vary in loudness by factors of 4 to 8 , or even more at very low frequencies. In the extreme it is possible for individual tones to drop below the threshold of hearing. In the ever-changing parade of tones and complex sounds that comprise music, those phenomena are not as destructive as they may appear to be. However, in controlled listening tests or experiments where more than one listener is involved, it does mean that no two people will experience the same acoustical stimulus, and that no one will experience precisely the sound radiated by the loudspeaker.

As a means of simplifying both the measurement and the presentation of the data it has become commonplace to use 1/3-octave bandwidth filtered pink noise in measurements of frequency response in rooms. Figure $3 b$ shows such a measurement result. Figure 3c shows the swept-tone measurement of $3 \mathrm{a}$ superimposed on the 1/3-octave measurement of $3 \mathrm{~b}$ illustrating how, in the simplification, some possibly important variations have been disguised. Still the method is useful and it does retain much of the information about the interactions of room and loudspeaker.

Figure 4 shows a set of smoothed 1/3-octave measurements made in a listening room set up for sound quality evaluations. The microphone was one meter above the floor, at approximately the ear height of a seated listener and was moved, in turn, to each of the six numbered positions. The sound source for all the measurements was a loudspeaker at position $B$. It is evident that at no two positions are the measurements the same. At individual frequencies, or 1/3-octave bands, the fluctuations are considerable and in some cases there is even a shift in the overall bass/treble energy balance. Such changes in spectral balance are easily discerned in assessments of sound quality or timbre.

In spite of the differences, there are some features that the series of six curves have in common. For example, there are dips at about $100,160,800$, and $2500 \mathrm{~Hz}$ that appear, more or less, in all of the measurements. If we look at the anechoic data for this loudspeaker, in Figure 5, evidence for the dips at 800 and $2500 \mathrm{~Hz}$ and the roll-off of high-frequency energy is apparent in the off-axis measurements. Obviously the room communicates this off-axis sound radiation to the listener positions with considerable efficiency. There is, however, no suggestion as to the cause of the dips at lower frequencies.

Averaging the six curves of Figure 4 produces Figure 6a 
which illustrates very clearly the features being discussed. Substituting a loudspeaker with performance similar to that shown in Figure 1 and repeating the set of measurements and averaging produced the curve shown in Figure $6 \mathrm{~b}$. The well-behaved on-and off-axis output of the loudspeaker has, in essence, been communicated to the listener positions. In listening tests, the differences in sound quality are easily audible and in terms of perceived reproduction accuracy the loudspeaker of Figure 1 (Figure $6 \mathrm{~b}$ ) was consistently preferred. There remain, however, the dips at 100 and $160 \mathrm{~Hz}$ to be explained.

The sound output from any conventional loudspeaker of practical size is omni-directional at low frequencies, that is, the sound is radiated equally in all directions. The room boundaries, floor, walls, or ceiling that are close to the loudspeaker therefore reflect the sound from the loudspeaker back onto the listening room. At the listener positions there will consequently be frequencies at which the direct sound from the loudspeaker is one-half wavelength out of step with the delayed sound reflected from these nearby surfaces, and the two sounds cancel. In the given example, the $\operatorname{dip}$ at $100 \mathrm{~Hz}$ is due to such destructive interference between the direct sounds and sounds reflected from the back wall and also from the adjacant side wall; the smaller dip at $150 \mathrm{~Hz}$ is due to a reflection from the floor. The fact that both loudspeakers measured in Figure 6 exhibit dips at the same frequencies is because care was taken to ensure that the woofers were in precisely the same location in both cases. Moving the woofer with respect to the nearby room surfaces would change the frequencies at which the acoustic wave cancellation and the frequency-response dips occur. Clearly the bass performance of a loudspeaker, or a musical instrument with significant lowfrequency output, will be substantially influenced by its position in the room.

Similarly, a listener close to a room boundary will experience wave cancellations at his ears due to the reflected sounds. Therefore, in any experiment or listening evaluation involving low frequencies, serious consideration must be given to a number of physical factors, any or all of which can cause audible differences that may be significant to the result of the tests. In evaluations of loudspeakers, for example, the effects are easily large enough to swamp any real differences that exist between many products.

There are several ways of dealing with problems of this kind. Obviously, if it is possible, the room itself should be con- 
structed and furnished with the acoustical objectives in mind. There is even a proposal for a standardized listening room that could be useful for a variety of purposes including, especially, experiments in which the room is a significant factor and where it is wished to compare data acquired in different laboratories (see IEC Draft Publication 268-13).

In the conduct of experiments, the least that should happen is that the properties of the acoustical coupling of sound source to listener through the room should be measured and documented. If it is not possible to achieve a satisfactory coupling between specific source and listener positions, the imperfections should be dealt with by varying the source and listener positions from time to time during the experiment. In this manner the irregularities are at least partially a veraged out.

\section{Conclusions}

It is evident that acoustical factors related to room dimensions, finishing, and furnishing are significant to the nature of the sound field in the room. It is further evident that the specific location of a sound source, whether this is a sound producer (a musical instrument) or a sound reproducer (a loudspeaker) can influence the sound reaching the listening area. These factors, combined with the influence of listener position, mean that if the results of listening experiences in a room are to have more than passing relevance, the acoustical factors must be given serious consideration.

It has long been argued, in the hi-fi field, that choosing a loudspeaker is a matter of personal taste, rather akin to selecting a musical instrument. Since our personal tastes in so many things differ, why not in this also? In our laboratory, we have conducted controlled listening tests for over a decade. These have been used as an aid to loudspeaker manufacturers, to audio journalists preparing product reviews, and as a basis for psychoacoustic studies of listening tests themselves. As the procedures have been improved through knowledge of the kind discussed here, the experimental results have changed. Even in the early years, with rather rudimentary experimental controls, it was evident that individual opinions on loudspeakers were not nearly as variable as many people would have us believe. Nowadays, it is routine to get reasonable agreement, within a group of listeners, on assessments of loudspeakers that are much better and more similar to each other than those involved in the earlier tests. The experimen- 
tal controls that have led to these results are mainly physical: the careful preparation of the experiment so that the sound at the listener's ears is not accidental but due to the experimental parameter or device under examination.

Some years ago, to illustrate in a partially empirical way that the methods work, the graphs of Figures 7 and 8 were prepared. A number of observations derive from an examination of these illustrations of anechoic measurements on two groups of loudspeakers, one group selected on the basis of consistent listener opinion of a favorable kind and the other group selected on the basis of severe listener criticism.

The main observation is that above about $300 \mathrm{~Hz}$ there is little consistency among the measurements of the "poor" loudspeakers, whereas the "good" loudspeakers seem to exhibit more of a common tendency, indicating, perhaps, a single objective. Below $300 \mathrm{~Hz}$ the relatively consistent behavior exhibited by all loudspeakers, good or bad, is evidence of the fact that woofer and loudspeaker enclosure design are now well-defined engineering problems that have straightforward solutions. The tendency for the good loudspeakers to exhibit more uniform overall frequency responses is a simple indication that this familiar virtue of any audio component can be recognized in controlled loudspeaker listening tests. That this virtue is not always recognized in other circumstances is indicated by the number of well-known, expensive, and, in certain circles, highly regarded loudspeakers that appear in the "poor" classification. Obviously, returning to Figures 1 and 2, the examples chosen are specific illustrations of "good" and "poor" sounding loudspeakers. The explanation for this situation and for the continued commercial success of technically imperfect loudspeakers lies principally in the quality of judgment that is possible under normally imperfect listening comparisons and in the inadequate technical specification commonly available from manufacturers.

These problems at the present time affect all levels of endeavor in audio, from casual listening in the home to psychoacoustic research. The former could be considered merely a nuisance, the latter, however, is an unnecessary impediment to science. 
$z \frac{2}{x}$

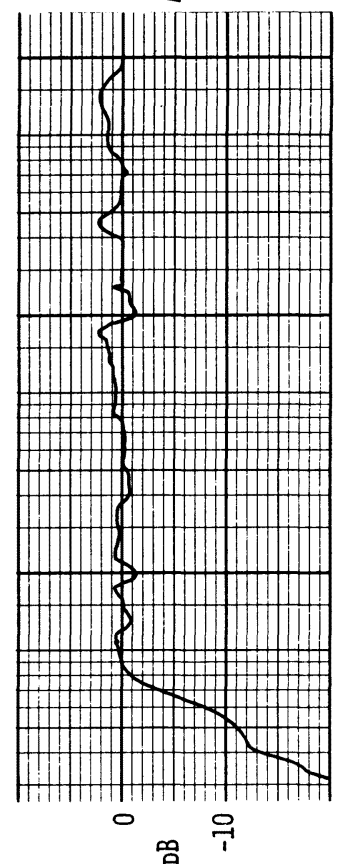

웅 웅

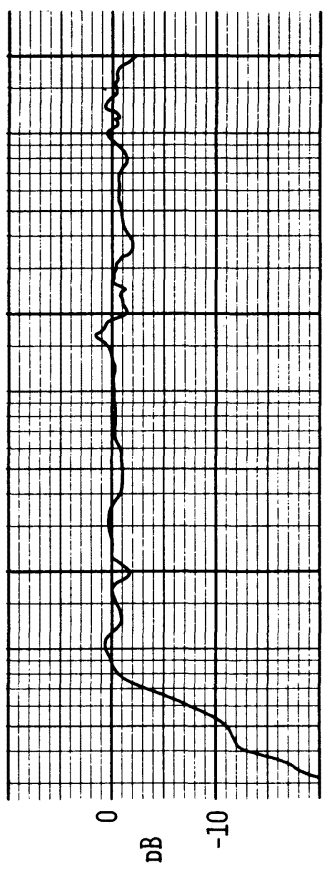

¿웅

寅噯

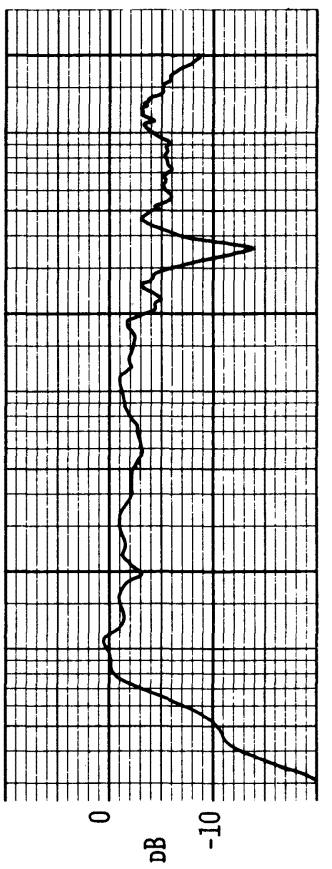

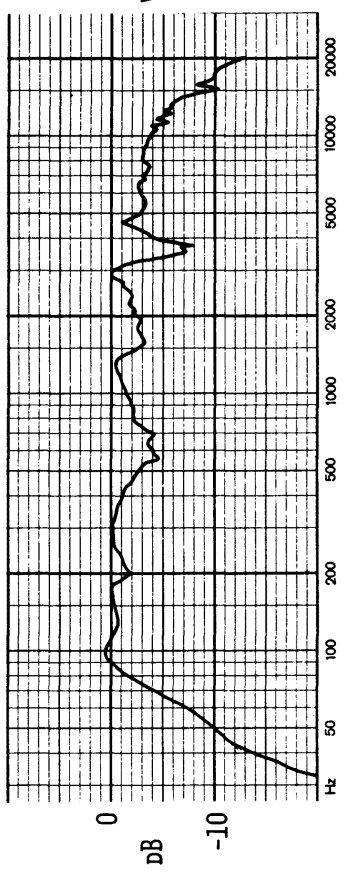

离

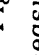

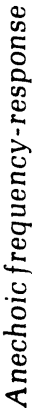


ต

$z \stackrel{n}{x}$

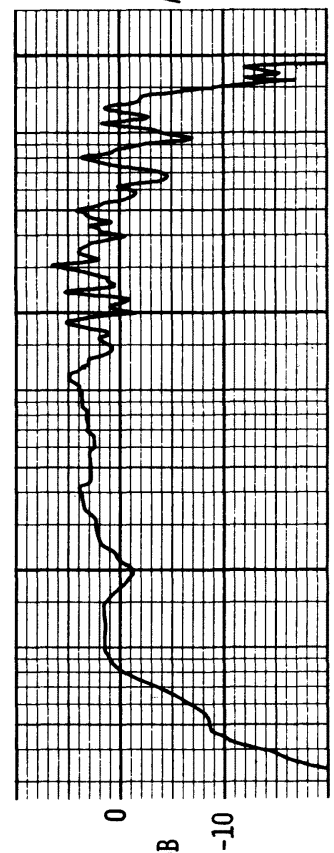

ㅇํำ
홓

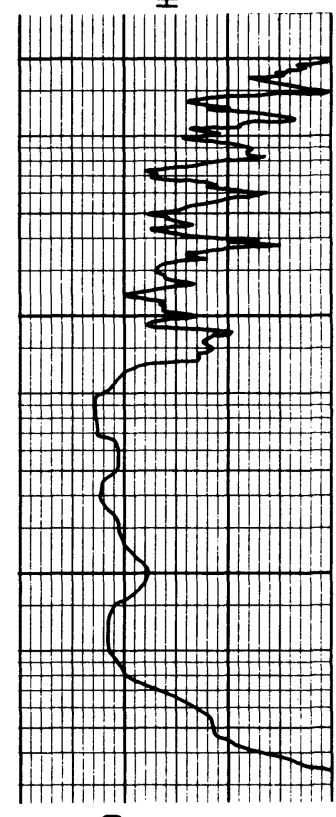

$\circ$
¿ 훙

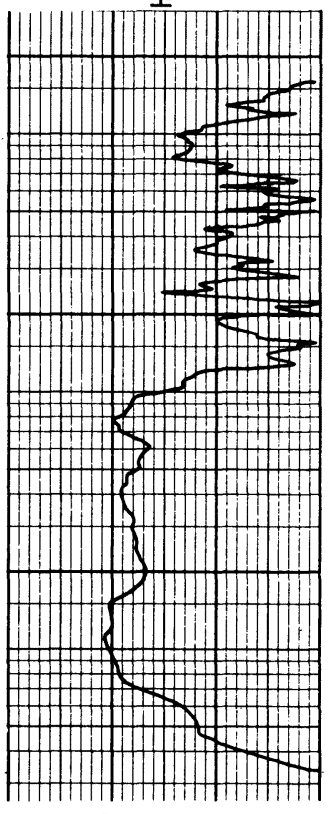

- 은
它

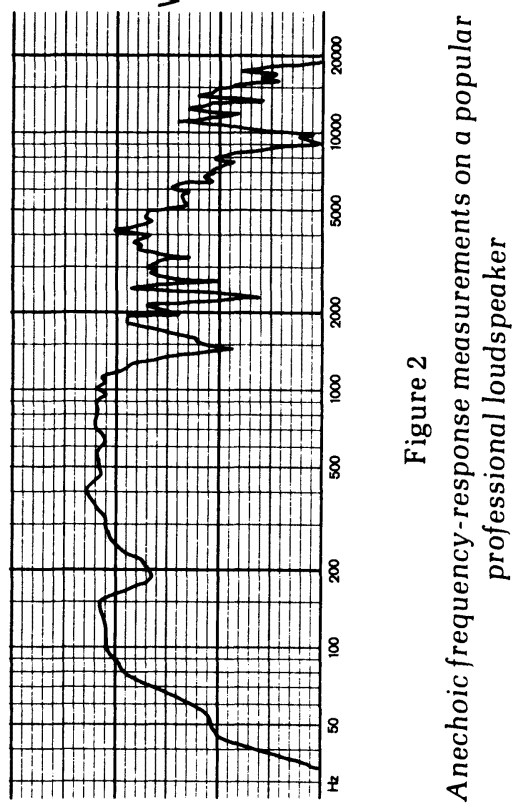

ต 움 

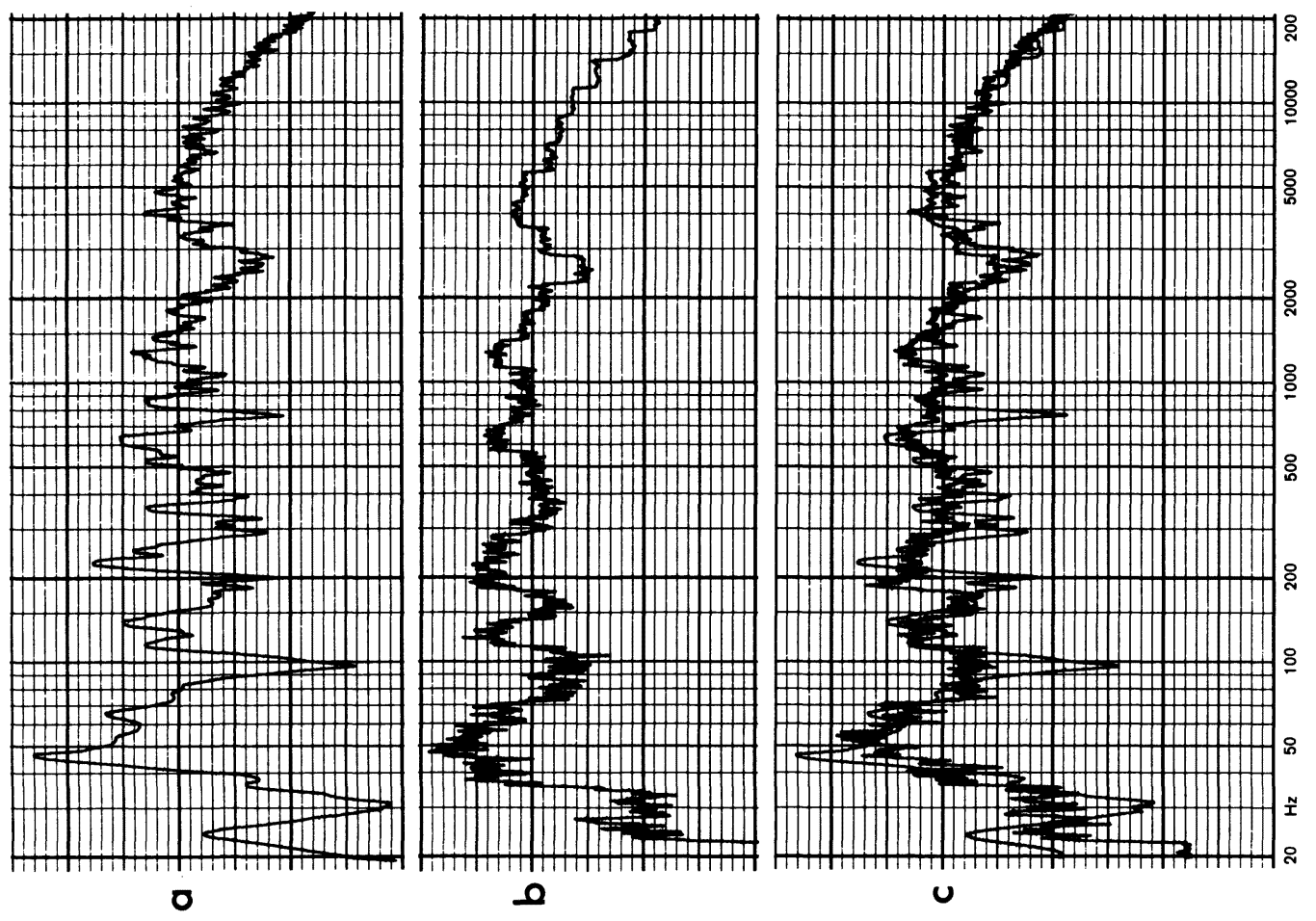

牙

is 3

¿

$\pm$.

$\because 30$

焉

艺疍

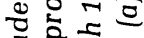

ह

23

동웡

क के

๖ วิ ล

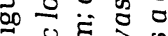

约

क 잉

है

은로 논

$0 \overrightarrow{0} 0$

$\infty=\overrightarrow{0}$

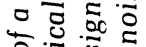

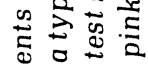

ถ ฐ ฐ

ปร

范范 

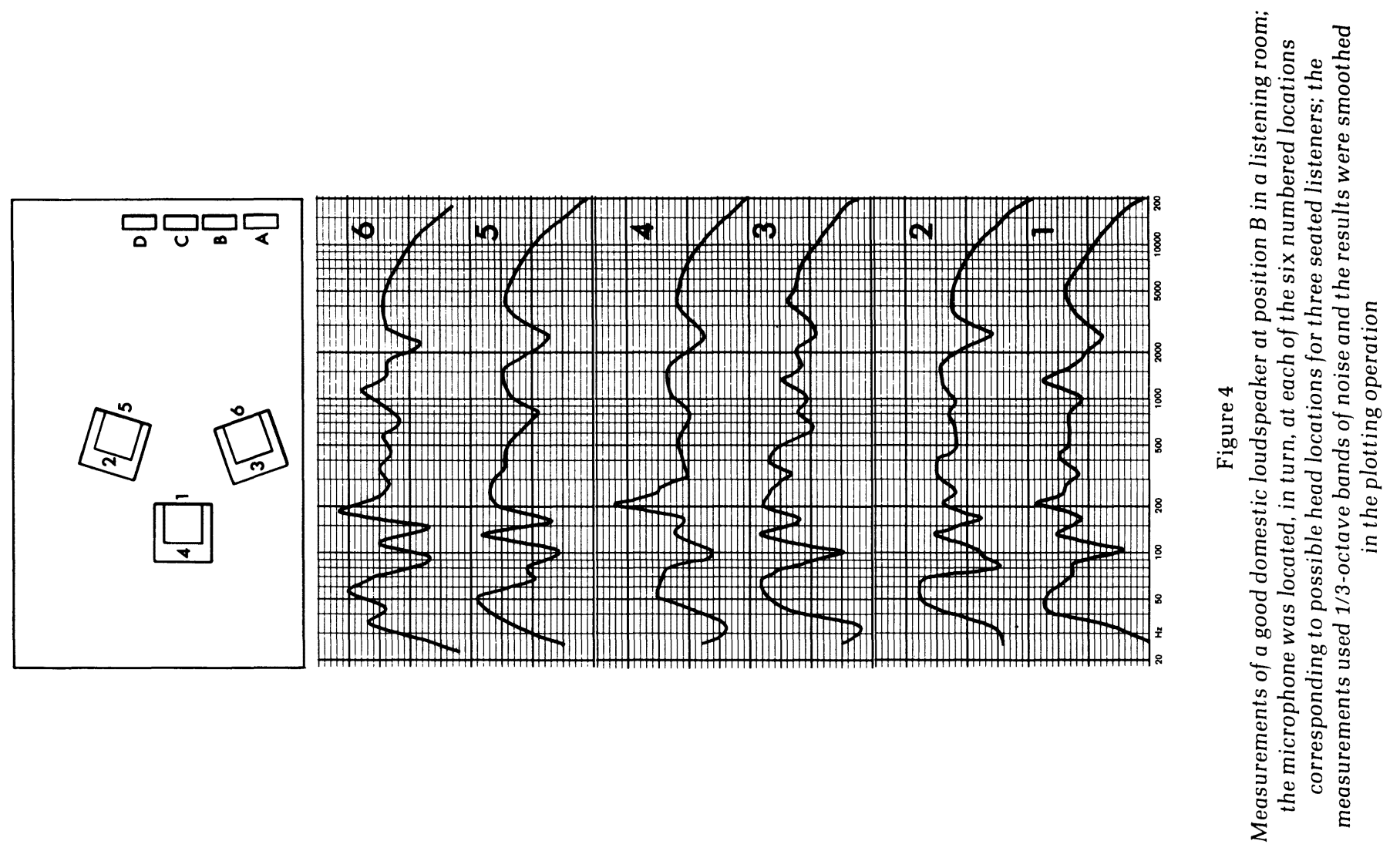
z

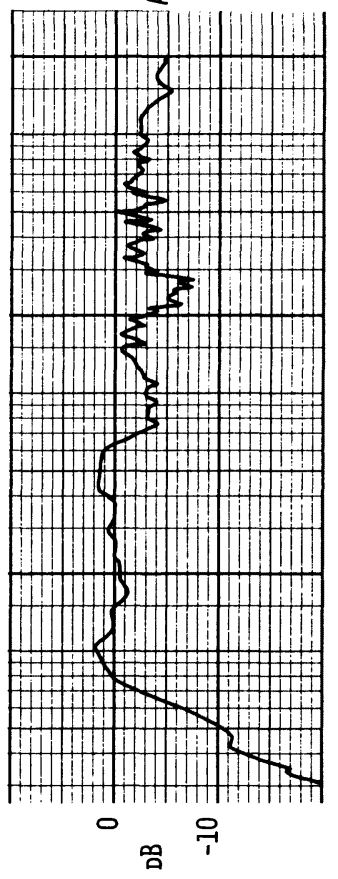

응 웅

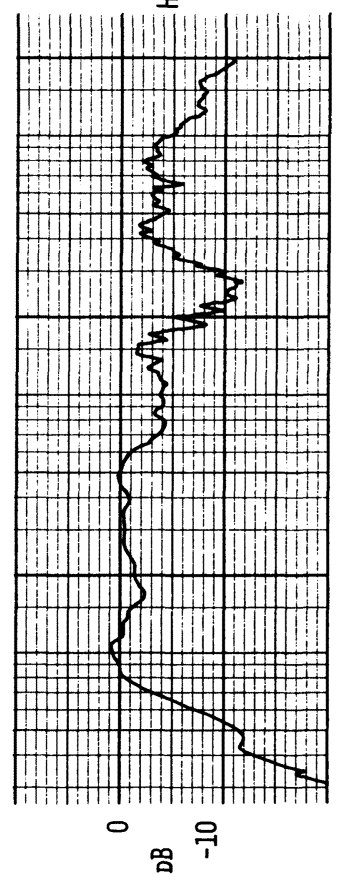

¿ㅇ

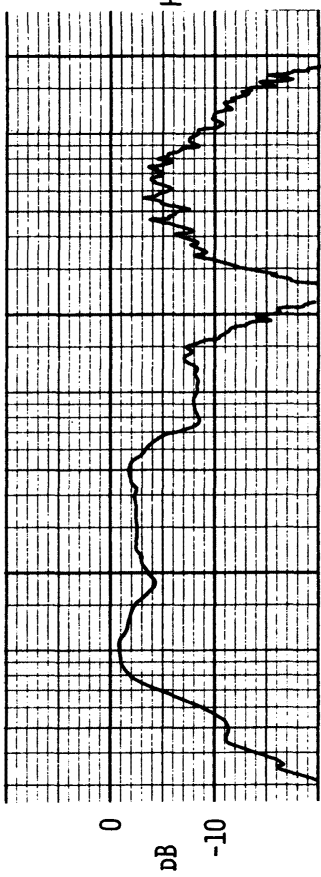

寅点

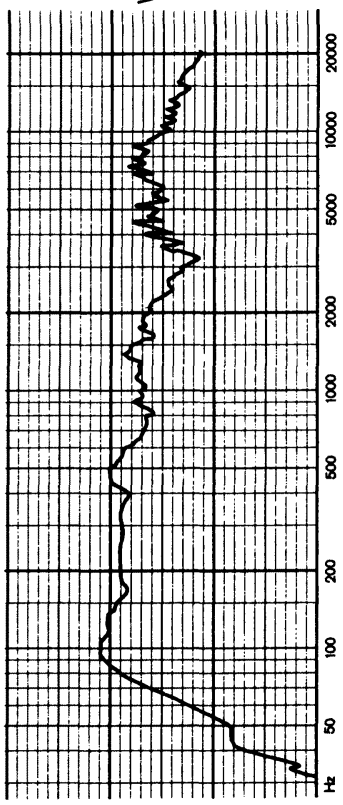

뭄
$\Xi$

ฮู

ว

氙

क्

으

$\stackrel{5}{ \pm}$

这

壳立

1) ह

๑

औึ क

的 ญ

\&

ह

के

क्ञ

टे

ఏ్

จ

.

通 

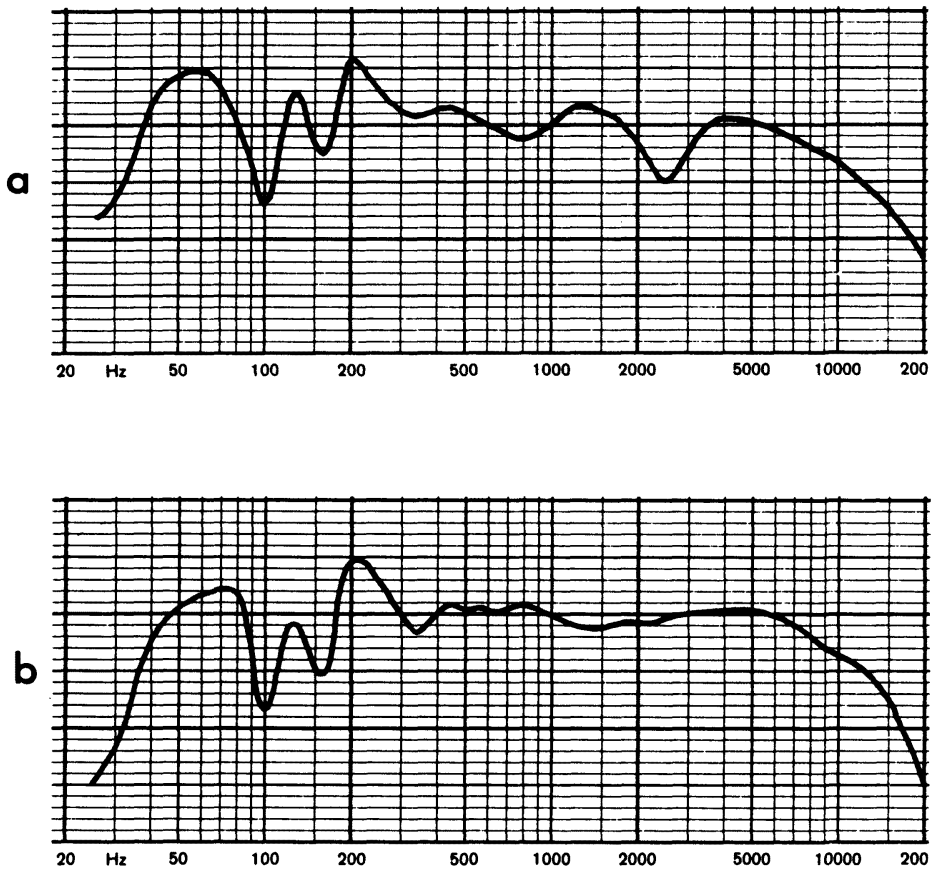

Figure 6

(a) Average of the six room measurements shown in Figure 4; (b) average of six room measurements using a loudspeaker with anechoic performance measurements similar to those shown in Figure 1 

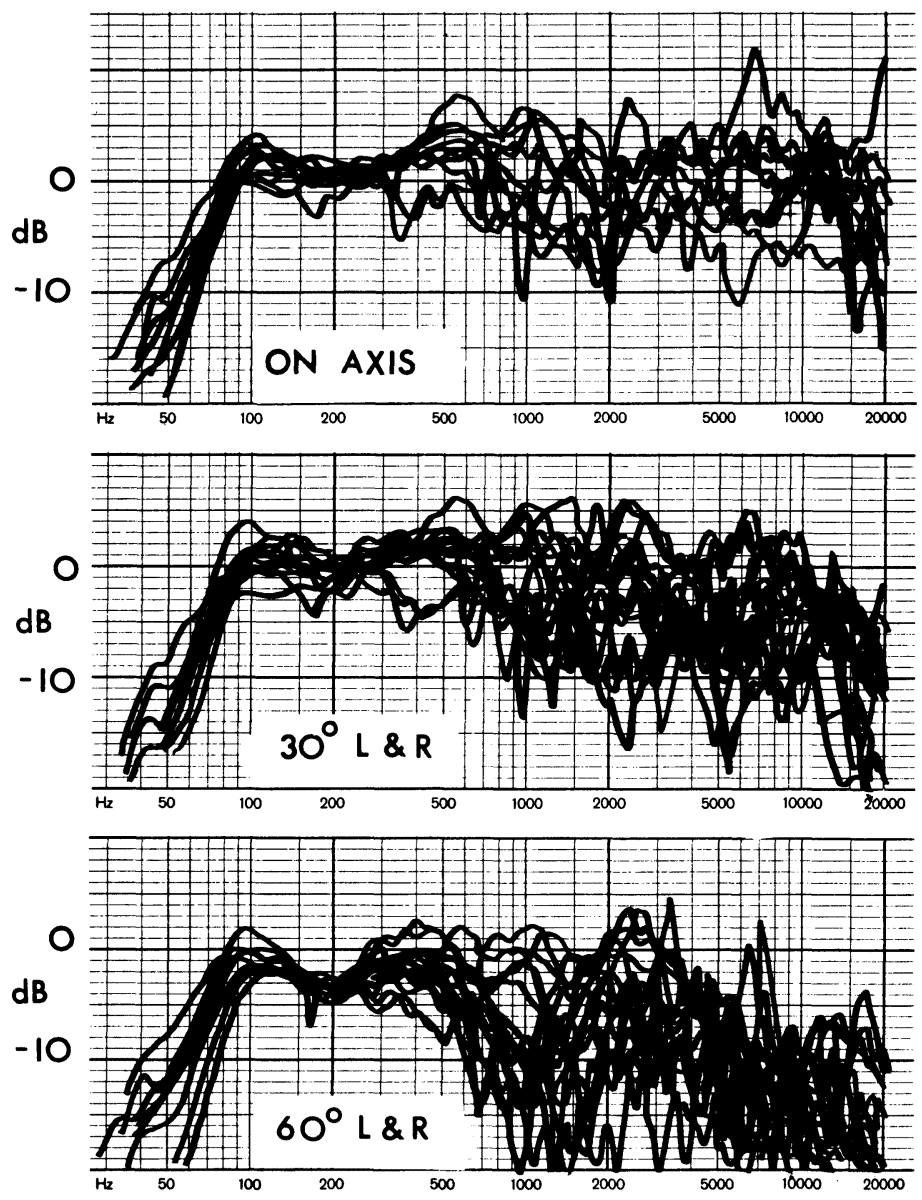

Figure 7

Superimposed anechoic measurements on ten loudspeakers identified by listeners as being consistently low on a scale of "fidelity" or "accuracy" 

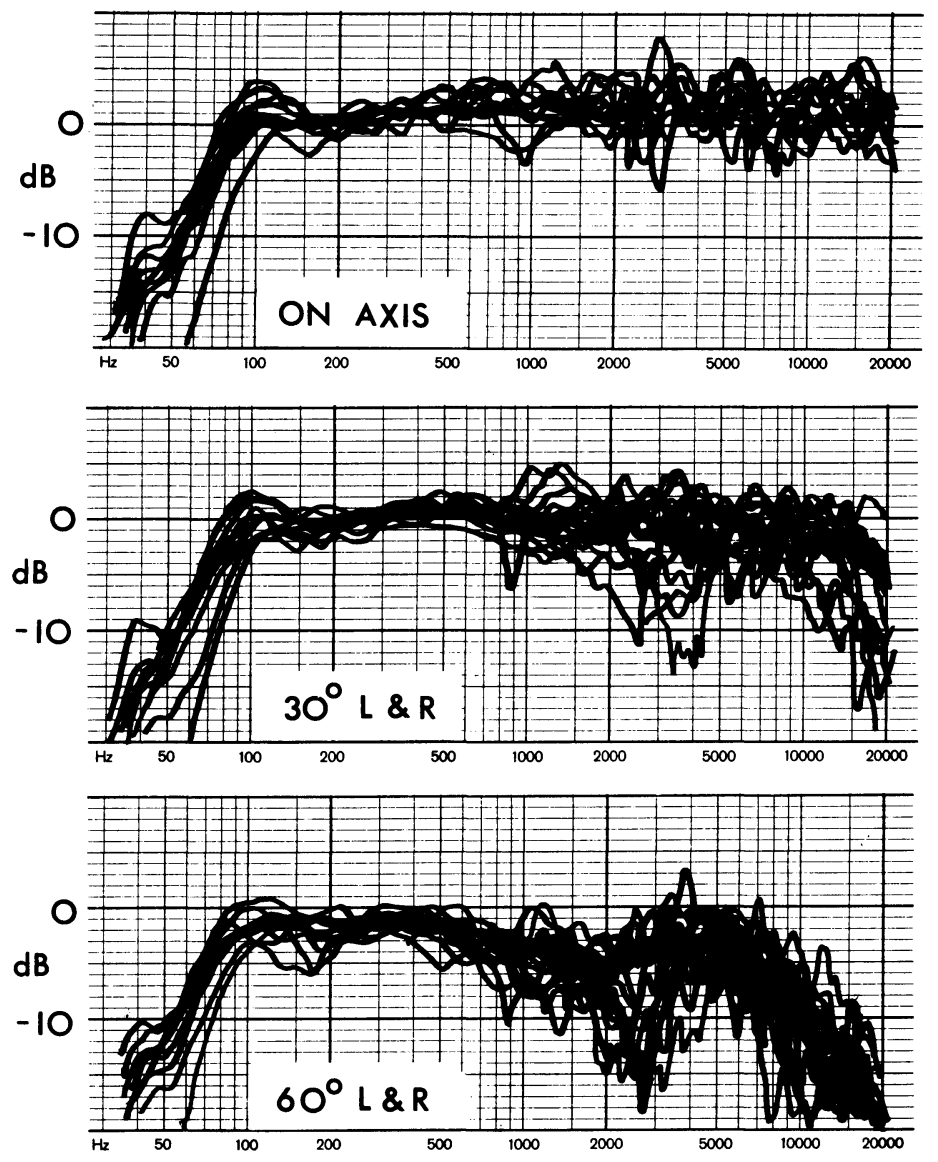

Figure 8

Superimposed anechoic measurements on ten loudspeakers identified by listeners as being consistently high on a scale of "fidelity" or "accuracy" 


\section{REFERENCES}

GABRIELSSON, A. and SJÖGREN, $\mathrm{H}$.

1979: "Perceived Sound Quality of Sound-Reproducing Systems," Journal of the Acoustical Society of America, LXV/4, 1019-33.

"Sound System Equipment, Part 5: Loudspeakers." Geneva: International Electrotechnical Commission, Publication 268-5 (1972) (currently under revision).

"Sound System Equipment, Part 13: Listening Tests on Loudspeakers." Geneva: International Electrotechnical Commission, Draft Publication 268-13 (in press).

TOOLE, F.E.

1977: "Speakers: Parts 1-4," AudioScene Canada, XIV/3, 19; XIV/4, 41; XIV/5, 29; XIV/7, 46.

1979: "High Fidelity in the Control Room, Why Not?" dB, XIII/2, 30-33.

1982a: "Listening Tests-Turning Opinion Into Fact," Journal of the Audio Engineering Society, XXX/6, 431-45.

1982b: "Subjective Measurements of Loudspeaker Sound Quality," presented at the 72nd Convention of the Audio Engineering Society, Oct. 1982. Preprint No. 1900. 